\title{
Cor triatriatum dexter in children: Literature review and case report
}

\author{
Afksendiyos Kalangos, MD, ${ }^{\mathrm{a}}$ Nataliia Shatelen, MD, ${ }^{\mathrm{b}}$ Vitaly Demyanchuk, MD, ${ }^{\mathrm{b}}$ Nataliia Ruban, MD, ${ }^{\mathrm{b}}$ \\ Panagiotis Sfyridis, MD, ${ }^{\mathrm{a}}$ and Borys Todurov, $\mathrm{MD},{ }^{\mathrm{b}}$ Athens, Greece, and Kiev, Ukraine
}

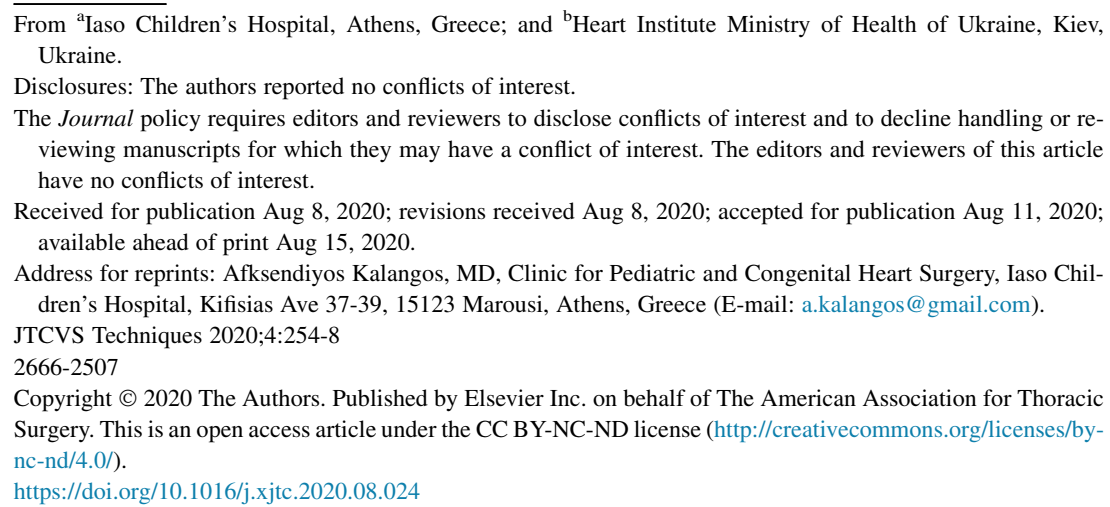

Video clip is available online.

Cor triatriatum dexter (CTD) is one of the rarest congenital cardiac malformations in which there is an abnormal septation of the right atrium (RA) due to the failure of regression of the embryonic right-sided sinus venosus valve. ${ }^{1}$ We present our experience regarding a young patient with CTD associated with severe tricuspid regurgitation and review the 13 pediatric cases of CTD previously reported in the literature who underwent surgery (Table 1). ${ }^{1-12}$ Informed consent was received for our patient.

A female child was initially seen at our institution at the age of 5 years of age because of frequent episodes of palpitation on exertion. Her electrocardiogram exhibited a normal sinus rhythm with a heart rate of 100 beats $/ \mathrm{min}$. Peripheral arterial oxygen saturation was normal $(99 \%)$. Transthoracic echocardiography (TTE) detected the presence of a wide unrestrictive membrane in an enlarged RA and revealed mild-to-moderate tricuspid regurgitation with no evidence of Ebstein disease or any intracardiac shunting.

At regular clinical examinations, the patient began demonstrating progressive dyspnea, palpitations, and fatigue on moderate exertion. Her latest TTE control, at the age of 9 years, confirmed the presence of this wide membrane in the RA, which was protruding toward the tricuspid

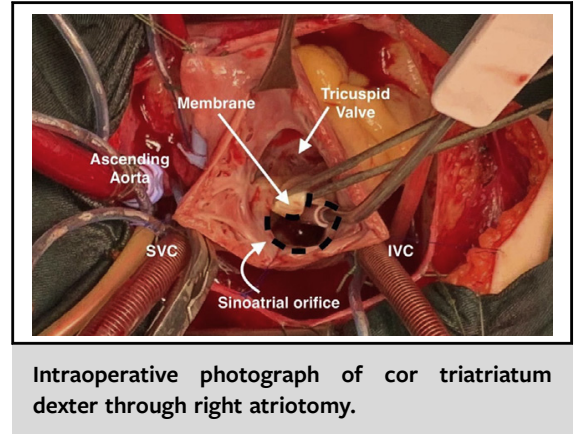

\begin{abstract}
CENTRAL MESSAGE
Cor triatriatum dexter is a rare congenital defect. Early cyanosis, Budd-Chiari syndrome, and progressive dyspnea are the most frequent symptoms. Membrane resection is indicated for symptomatic patients.
\end{abstract}

See Commentaries on pages 259 and 261. valve (TV) during diastole and also revealed severe central regurgitation during systole (Video 1).

At surgery, the RA was opened and a nonobstructive membrane extending across the RA-which was dividing it into 2 chambers, with both caval veins and the coronary sinus on one side and the TV and RA appendage on the other-was exposed (Figure 1). This membrane, which was completely covering the TV leaflets, was carefully resected starting from the upper and lower parts of its anterior unobstructed sinoatrial orifice. After resection, the TV was exposed and its analysis confirmed the suspicion of annular dilatation as well as the presence of a retracted fibrotic septal leaflet with limited mobility. Tricuspid annuloplasty with a Carpentier Edwards tricuspid ring (Edwards Lifesciences, Irvine, Calif) size 28, and a stitch closure of the anteroseptal commissure were performed. Postrepair transesophageal echocardiography confirmed the satisfactory surgical correction with no residual leak. The postoperative course was uneventful. 
TABLE 1. Reported surgical cases of cor triatriatum dexter in children

\begin{tabular}{|c|c|c|c|c|c|}
\hline Study & $\begin{array}{l}\text { Age at } \\
\text { surgery } \\
\text { and sex }\end{array}$ & $\begin{array}{c}\text { Additional } \\
\text { malformations }\end{array}$ & Symptoms & Surgery & Outcome \\
\hline $\begin{array}{l}\text { Doucette and } \\
\text { Knoblich, } 1963^{1}\end{array}$ & $6 \mathrm{wk}, \mathrm{M}$ & $\begin{array}{l}\text { PA, HRV, HTV, PFO, } \\
\text { ASD }\end{array}$ & Cyanosis & Modified Potts shunt & $\begin{array}{c}\text { Death after } \\
\text { surgery }\end{array}$ \\
\hline Folger, $1968^{2}$ & $9 \mathrm{y}, \mathrm{F}$ & $\begin{array}{l}\text { PA, HRV, HTV } \\
\text { PDA, ASD }\end{array}$ & $\begin{array}{l}\text { Cyanosis } \\
\text { from } 3 \text { mo }\end{array}$ & $\begin{array}{l}\text { Pulmonary valvulotomy } \\
\text { and tricuspid } \\
\text { valvulotomy }\end{array}$ & $\begin{array}{l}\text { Death after } \\
\text { surgery }\end{array}$ \\
\hline Folger, $1968^{2}$ & $51 / 2 \mathrm{mo}, \mathrm{M}$ & $\begin{array}{l}\text { Supravalvular and } \\
\text { pulmonary valve } \\
\text { stenosis, PDA, ASD }\end{array}$ & $\begin{array}{c}\text { Cyanosis and } \\
\text { dyspnea } \\
\text { on exertion }\end{array}$ & $\begin{array}{l}\text { ASD closure and opening } \\
\text { of supravalvular PS }\end{array}$ & $\begin{array}{l}\text { Death after } \\
\text { surgery }\end{array}$ \\
\hline Jones and Niles, $1968^{3}$ & $4 \mathrm{mo}, \mathrm{M}$ & $\begin{array}{l}\text { HRV, tricuspid atresia, } \\
\text { ASD, VSD }\end{array}$ & Cyanosis & $\begin{array}{l}\text { Potts shunt at } 4 \text { mo } \\
\text { Glenn procedure at } 8 \mathrm{y}\end{array}$ & $\begin{array}{l}\text { Death at } 10 \\
\text { y due to } \\
\text { obstruction } \\
\text { of RA flow } \\
\text { by the large } \\
\text { membrane }\end{array}$ \\
\hline Nakano et al, $1974^{4}$ & $7 \mathrm{y}, \mathrm{F}$ & $\begin{array}{l}\text { ASD, peri-membranous } \\
\text { VSD, HTV }\end{array}$ & $\begin{array}{l}\text { Cyanosis } \\
\text { early in life, } \\
\text { fatigability and } \\
\text { progressive } \\
\text { dyspnea on } \\
\text { severe exertion } \\
\text { after the first } \\
\text { year of life }\end{array}$ & $\begin{array}{l}\text { Complete membrane } \\
\text { resection } \\
\text { Direct closure of VSD }\end{array}$ & Alive \\
\hline Mazzuco et al, $1983^{5}$ & $5 \mathrm{mo}, \mathrm{F}$ & $\begin{array}{l}\text { LSVC draining into the } \\
\text { LA, separate draining } \\
\text { of hepatic veins into the } \\
\text { RA }\end{array}$ & Cyanosis & $\begin{array}{l}\text { Complete membrane } \\
\text { resection } \\
\text { Pericardial patch } \\
\text { reconstruction of a new } \\
\text { interatrial septum }\end{array}$ & $\begin{array}{l}\text { Alive } 5 \mathrm{y} \\
\text { after surgery }\end{array}$ \\
\hline Kolouskova et al, $1996^{6}$ & $6 \mathrm{y}, \mathrm{M}$ & - & $\begin{array}{l}\text { Exudative } \\
\text { enteropathy } \\
\text { syndrome }\end{array}$ & $\begin{array}{l}\text { Complete membrane } \\
\text { resection }\end{array}$ & Alive \\
\hline Alkhulaifi et al, $1999^{7}$ & $12 \mathrm{y}, \mathrm{M}$ & - & Ascites & $\begin{array}{l}\text { Complete membrane } \\
\text { resection }\end{array}$ & Alive \\
\hline Barrea et al, $2009^{8}$ & $4 \mathrm{mo}, \mathrm{F}$ & Large PFO & Cyanosis & $\begin{array}{l}\text { Complete membrane } \\
\text { resection }\end{array}$ & Alive \\
\hline Galli et al, $2009^{9}$ & $1 \mathrm{mo}, \mathrm{F}$ & ASD, PDA & Cyanosis & $\begin{array}{l}\text { Complete membrane } \\
\text { resection and ASD } \\
\text { closure }\end{array}$ & $\begin{array}{r}\text { Alive at } 16 \text { mo } \\
\text { after surgery }\end{array}$ \\
\hline Hoye et al, $2010^{10}$ & $5 \mathrm{~d}, \mathrm{~F}$ & PFO, SVC stenosis & Cyanosis & $\begin{array}{l}\text { Complete membrane } \\
\text { resection, PFO closure } \\
\text { and pericardial patch } \\
\text { enlargement of SVC }\end{array}$ & Alive \\
\hline Alghamdi, $2016^{11}$ & $15 \mathrm{~d}, \mathrm{~F}$ & - & Cyanosis & $\begin{array}{l}\text { Complete membrane } \\
\text { resection at } 15 \mathrm{~d} \text { after } \\
\text { unsuccessful disruption } \\
\text { of the membrane by } \\
\text { catheterization }\end{array}$ & Alive \\
\hline
\end{tabular}


TABLE 1. Continued

\begin{tabular}{|c|c|c|c|c|c|}
\hline Study & $\begin{array}{l}\text { Age at } \\
\text { surgery } \\
\text { and sex }\end{array}$ & $\begin{array}{c}\text { Additional } \\
\text { malformations }\end{array}$ & Symptoms & Surgery & Outcome \\
\hline Rao et al, $2018^{12}$ & $10 \mathrm{mo}, \mathrm{M}$ & $\begin{array}{l}\text { Large ASD, PS, mild } \\
\text { HRV, LSVC }\end{array}$ & Cyanosis & $\begin{array}{l}\text { Pulmonary balloon } \\
\text { valvulotomy at } 4 \text { mo } \\
\text { Complete membrane } \\
\text { resection, ASD closure } \\
\text { with autologous } \\
\text { pericardium }\end{array}$ & Alive \\
\hline Present case, 2020 & $9 \mathrm{y}, \mathrm{F}$ & Severe TR & $\begin{array}{l}\text { Fatigability } \\
\text { and dyspnea } \\
\text { on exertion }\end{array}$ & $\begin{array}{l}\text { Complete membrane } \\
\text { resection and TV repair }\end{array}$ & Alive \\
\hline
\end{tabular}

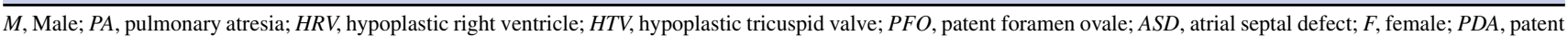
ductus arteriosus; $V S D$, ventricular septal defect; $R A$, right atrium; $L S V C$, left superior vena cava; $L A$, left atrium; $S V C$, superior vena cava; $P S$, pulmonary stenosis; $T R$, tricuspid regurgitation; $T V$, tricuspid valve.

\section{DISCUSSION}

Eustachian and thebesian valves as remnants of the sinus venosus valves are not uncommon. ${ }^{13}$ They rarely produce clinical symptoms in children without any other significant structural heart defects. ${ }^{14,15}$ In contrast, the septation of the
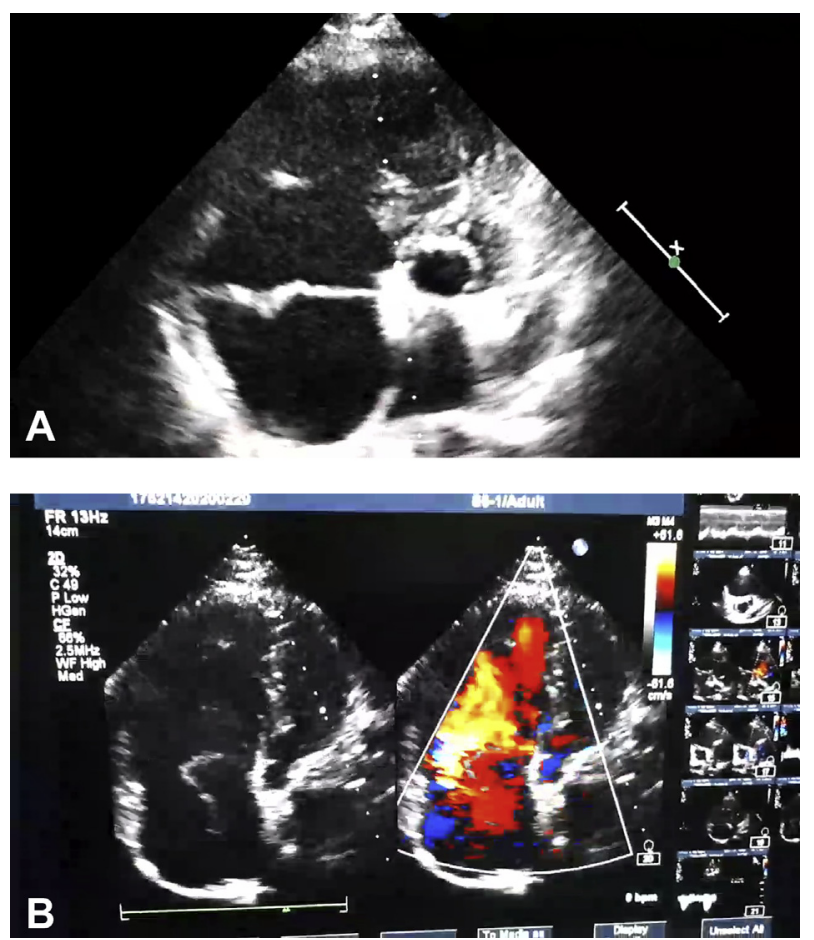

VIDEO 1. Preoperative 2-dimensional transthoracic echocardiography demonstrating the presence of a membrane separating the right atrium into 2 parts that was protruding into the right ventricle through the tricuspid orifice during diastole. The septal tricuspid leaflet is thickened and immobile (A). Severe central tricuspid insufficiency during systole with color Doppler (B). Video available at: https://www.jtcvs.org/article/S2666-2507 (20)30399-0/fulltext.
RA with a membrane between its smooth and trabeculated portions may lead to subsequent malformations of the right heart structures in utero. In anatomical studies of hypoplastic right heart structures, a prominent eustachian valve directing the abnormal fetal flow across the atrial septal defect (ASD) has been documented in up to $80 \%$ of cases, including CTD in $25 \%$ of them. ${ }^{16}$ However, it cannot clearly be determined whether this abnormal fetal flow due to the persistent presence of the RA remnants promotes the genesis of hypoplastic right heart structures or vice versa the presence of hypoplastic right heart structures potentially contributes to the persistence of these RA remnants.

Based on the reported cases presented in Table 1, the time of onset and the severity of the various clinical manifestations depend primarily on the following 6 factors in children. (1) The size of the sinoatrial orifice(s), the sinus

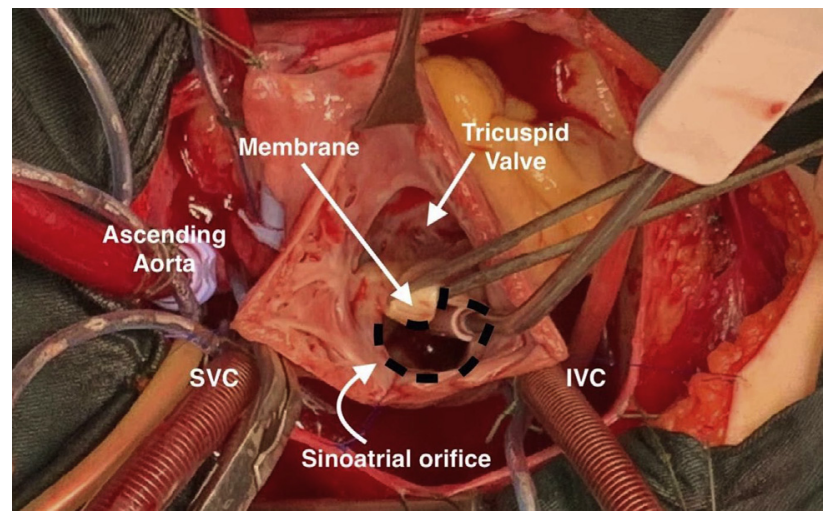

FIGURE 1. Operative photograph of cor triatriatum dexter through an oblique right atriotomy. The dotted black circle between the membrane and the right lateral wall of the RA represents the sinoatrial orifice, which connects the smooth sinus part to the trabeculated part of the RA. The sinus part receives blood flow from the SVC, IVC, and coronary sinus and the trabeculated part contains the TV and the right appendage. SVC, Superior vena cava; $I V C$, inferior vena cava. 
portion of the RA receiving the superior, and inferior venae cavae blood flow return. The size of this orifice determines the degree of blood flow obstruction from the smooth sinus part of the RA toward its trabeculated part, which contains the TV. (2) The presence of an associated ASD, its size determining the quantity of right-to-left shunting in correlation with the degree of obstruction of the sinoatrial orifice(s). ${ }^{1-5,8-10,12}$ (3) The presence of associated RV and TV hypoplasia resulting in limited RV compliance and therefore increasing right-to-left shunting. ${ }^{1-3,12}$ (4) The presence of functional TV obstruction created by the protrusion of the membrane through the tricuspid orifice during diastole $^{4,8,9,12}$ or the presence of TV insufficiency due to fibrosis and deformation induced by the repetitive traumatic effect of the membrane on the TV leaflets, as in our case. (5) The presence of associated right ventricular outflow tract obstruction at different levels. ${ }^{2,12,17}$ (6) Predominant obstruction of inferior vena cava flow by the RA membrane with no associated ASD. ${ }^{6,7}$

Eleven of the 14 pediatric cases reported in the literature presented with cyanosis early in life due to the presence of obstructive sinoatrial orifice(s) and an associated ASD of varying sizes. ${ }^{1-5,8-12}$ Two of these 14 cases also presented with Budd-Chiari syndrome with exudative enteropathy in one case ${ }^{6}$ and ascites in the other ${ }^{7}$ due to obstruction of the inferior vena cava flow by the RA membrane, in the context of an intact interatrial septum. As a sole symptom, progressive fatigue and dyspnea on exertion is consistent with associated TV dysfunction in the context of CTD and can contribute to its incidental diagnosis by echocardiography, especially in cases of unobstructive sinoatrial orifice(s) and no associated ASD, as in our case. Children with unobstructed sinoatrial orifice(s) are usually asymptomatic and generally do not need any treatment of their CTD unless they would undergo cardiac surgery or percutaneous interventions for other reasons.

Eight of 11 cases that presented with cyanosis early in life were operated on during the first 6 months after birth ${ }^{1-3,5,8-11}$ and the other 3 cases at the ages of 10 months, ${ }^{12} 7$ years, ${ }^{4}$ and 9 years. $^{2}$ In cases before 1980 , the diagnosis was often missed and either revealed during or after surgery at postmortem examination, ${ }^{1-4}$ although clinical and especially cardiac catherization findings, in retrospect, were suggestive of CTD. ${ }^{4,5}$ Three of the 5 cases of this early period, with cyanosis after birth and a missed preoperative diagnosis of CTD, were operated on during the first 6 months of life. Two of the patients died just after surgery ${ }^{1,2}$ and the other patient 10 years later due to the obstructive membrane. ${ }^{3}$ The other 2 cases $^{2,4}$ of this early period were operated on at a relatively advanced age despite the early onset of cyanosis after birth. One of them died after surgery due again to the missed prompt diagnosis of $\mathrm{CTD}^{2}$ and the other one survived thanks to the resection of the membrane, which was incidentally discovered during surgery. ${ }^{4}$ After 1980, the reported 9 cases, including ours, survived thanks to the complete resection of the membrane at the time of surgery. ${ }^{4-12}$

In the last 6 cases including ours, which were reported after 2009, accurate preoperative diagnosis of CTD relied entirely on TTE performance. ${ }^{8-12}$ Nowadays, cardiac magnetic resonance imaging may be very helpful in the diagnostic assessment of CTD, as an additional valuable tool, to delineate the membrane and assess better right ventricular volume and function. ${ }^{12}$

Although percutaneous catheter disruption of the obstructive membrane has been suggested as an alternative to surgical resection, this is not always technically feasible or possible. ${ }^{18}$ For example, Alghamdi ${ }^{11}$ reported a case of unsuccessful disruption that required surgical resection 1 week later. On the contrary, percutaneous ASD closure can be an alternative treatment to surgery in unobstructive CTD cases. ${ }^{19}$

In conclusion, CTD with associated ASD must be considered as a cause of persistent hypoxia after birth in newborns and infants and a rare cause of exercise-induced hypoxia later in life. Budd-Chiari syndrome in childhood can in exceptional cases also be a consequence of CTD. Although percutaneous catheter disruption of the membrane has recently been reported, surgical resection of the RA and excision of the membrane still remains the preferred treatment for symptomatic patients.

\section{References}

1. Doucette J, Knoblich R. Persistent right valve of the sinus venosus. So-called cor triatriatum dexter: review of the literature and report of a case. Arch Pathol. 1963; 75:105-12.

2. Folger GM. Supravalvular tricuspid stenosis. Am J Cardiol. 1968;21:81-7.

3. Jones RN, Niles NR. Spinnaker formation of sinus venosus valve. Circulation. 1968;38:468-73.

4. Nakano S, Kawashima Y, Miyamoto T, Kitamura S, Manabe H. Supravalvular tricuspid stenosis resulting from persistent right sinus venosus valve. Ann Thorac Surg. 1974; 17:591-5.

5. Mazzuco A, Bortolotti U, Gallucci V, Del Torso S, Pellegrino P. Successful repair of symptomatic cor triatriatum dexter in infancy. J Thorac Cardiovasc Surg. 1983;85:140-5.

6. Kolouskova S, Lebl J, Snajderova M, Zemkova D, Hrobonova V, Honek T, et al. Growth in children with the exudative enteropathy syndrome due to a congenital heart defect-cor triatriatum dexter. Cas Lek Cesk. 1996;135: 59-61.

7. Alkhulaifi AM, Serraf A, Planche C. Ascites and weight loss in a child: due to congenital division of the right atrium. Cardiol Young. 1999;9:335-7.

8. Barrea C, Rubay J, Wagner K, Ovaert C. Cor triatriatum dexter mimicking Ebstein disease. Circulation. 2009;120:e86-8.

9. Galli MA, Galletti L, Schena F, Salvini L, Mosca F, Danzi GB. A rare case of neonatal cyanosis due to "cor triatriatum dexter" and a review of the literature. J Cardiovasc Med. 2009;10:535-8.

10. Hoye DJ, Wilson EC, Fyfe DA, Guzzetta NA. Cor triatriatum dexter: a rare cause of neonatal cyanosis. Anesth Analg. 2010;110:716-8.

11. Alghamdi MH. Cor triatriatum dexter: a rare cause of cyanosis during neonatal period. Ann Pediatr Cardiol. 2016;9:46-8.

12. Rao S, Suntharos P, Najm H, Komarlu R. Cor triatriatum dexter with right ventricular hypoplasia: role of multimodality imaging in decision making. Echocar diography. 2018;35:2113-6.

13. Chiari H. Uber Netzbildungen in rechten Vorhofedes Herzens. Beit Path Anat. 1897;22:1-10.

14. Sehra R, Ensing G, Hurwitz R. Persistent Eustachian valve in infants: course and management in symptomatic patients. Pediatr Cardiol. 1998;19:221-4.

15. Martinez-Quintana E, Rodriguez-Gonzalez F. Focusing on cor triatriatum dexter and atrial septal defects. Tex Heart Inst J. 2014;41:567-8. 
16. Schutte D, Rowland D, Allen H, Schutte D, Rowland D, Allen H, et al. Prominent venous valves in hypoplastic right hearts. Prominent venous valves in hypoplastic right hearts. Am Heart J. 1997;134:527-31.

17. Haboub M, Drighil A. Successful balloon valvuloplasty of a subpulmonic membrane associated with cor triatriatum dexter: a case report. J Med Case Rep. 2019; 13:291.
18. Savas V, Samyn J, Schreiber TL, Hauser A, O'Neil WW. Cor triatriatum dexter: recognition and percutaneous transluminal correction. Catheter Cardiovasc Diagn. 1991;23:183-6.

19. Eckersley LG, Clements B, Shipton S. Exercise-induced hypoxia secondary to an atrial septal defect and cor triatriatum dexter. Cardiol Young. 2016; 26:793-5 